\title{
The Predictability of Management Forecast Error: A Study of Australian IPO Disclosures ${ }^{\star}$
}

\author{
Neil Hartnett \\ The University of Newcastle, Australia \\ Jennifer Römcke \\ The University of Newcastle, Australia
}

\begin{abstract}
Contemporaneous evidence of corporate revenue and profit forecasting error is provided in a different institutional context, Australian sharemarket initial public offerings. This article extends the literature on company forecast risk by incorporating new proxies for forecasting error (float motive, subscription price premium, range of activities and internationalisation) and by refining others. The study investigates the association between earnings forecast risk and conventional ex-ante uncertainty proxies used to explain IPO underpricing. Ex-ante and ex-post explanatory variables are distinguished and a forecast error prediction model is tested. The results show revenue forecast errors were smaller and less sensitive than those for profit. Strong associations are reported between forecast error and float motive, audit quality and unanticipated industry activity. The link between earnings forecast error and proxies for initial public offering underpricing is observed. Predictability was poor regarding individual company forecast error, but improved for portfolio average forecasting error (JEL D80, G14, M41, N27).
\end{abstract}

Keywords: error, forecast, IPO, prediction, profit, underpricing.

*This article is dedicated to my much-loved co-author and companion, Jennifer, who passed away in 2000. We wish to thank seminar workshop participants at the Universities of Melbourne and Newcastle, Australia, delegates of the IAAER 2nd Biennial International Accounting Research Conference/CIERA 33rd International Accounting Conference, Chicago, USA, 1998, delegates of the International Conference on Accounting and Governance, University of Naples, Italy, 1998, and two other anonymous referees, for their constructive comments on earlier drafts.

(Multinational Finance Journal, 2000, vol. 4, no. 1\&2, pp. 101-132)

(C) Multinational Finance Society, a nonprofit corporation. All rights reserved.

DOI: $10.17578 / 4-1 / 2-5$ 


\section{Introduction}

The accuracy of published financial forecasts has been the focus of accounting and finance researchers for many years. Most studies of management forecasting error have focused upon earnings per share estimates published by established companies as part of their periodic disclosure policy. ${ }^{1}$ Forecast research is growing within other contexts, such as with initial public offerings (IPOs). ${ }^{2}$

The study of forecast accuracy can be instructive with regard to several capital market issues. Information asymmetry and signalling research suggests forecast disclosure can be useful in conveying news about company value [Patell (1976), Penman (1980), Waymire (1984), Lev and Penman (1990)]. Therefore understanding the extent to which published forecasts can accurately predict the future should be of concern to the market: forecasts perceived as unreliable should be discounted whilst those considered more accurate should command greater attention.

Forecast research can also improve our understanding of the IPO underpricing phenomenon. It is generally accepted that underpricing is positively associated with the level of uncertainty surrounding business quality and the price that the firm's share will command once it begins trading: that is, the ex-ante uncertainty of the issue [Ritter (1984), Beatty and Ritter (1986)]. A number of proxies for ex-ante uncertainty have been associated with underpricing. Of interest to this paper, underpricing has been associated with auditor/investigating accountant reputation [Titman and Trueman (1986), Simunic and Stein (1987), Beatty (1989)], percentage of ownership retained by the vendor [Leland and Pyle (1977), Beatty (1989)], firm size [Chalk and Peavy (1986)], firm age [Beatty (1989)], number and nature of uses of proceeds [Beatty and Ritter (1986), Jog and Riding (1987)] and industry [Ritter (1984), Jog and Riding (1987)]. ${ }^{3}$ Nevertheless, the possible association between these

1. Daily (1971), McDonald (1973), Basi et al. (1976), Imhoff (1978), Ruland (1978), Jaggi (1980), Hassel and Jennings (1986).

2. Mak (1989), Keasey and McGuinness (1991), Hartnett (1993), Lee et al. (1993a), Pedwell et al. (1994), Chan et al. (1996), Baginski and Hassell (1997).

3. The relationship between underpricing and other ex-ante risk proxies has been considered in the literature (notably share price variance and underwriter reputation) but not 
variables and the precision of an IPO's published financial forecast has not been explicitly recognised. As the uncertainty surrounding company value and share price must necessarily relate to the uncertain nature of the firm's expected future cash streams, the above-mentioned proxies might reasonably convey information about the likely precision of a financial forecast published as part of an IPO, and so influence the degree of information asymmetry and offer pricing. ${ }^{4}$

In the context of IPOs, the company prospectus provides an important source of information for investors. It contains information on past performance (if any), the present financial situation and, to varying degrees, expected future direction. In some markets the inclusion of information about an IPO company's future trade prospects is now mandatory (eg. New Zealand). In other settings, disclosure is voluntary and reasonably common (eg. Australia, Canada, UK), or rare and discouraged (USA). ${ }^{5}$ In Australia, Section 1022(1) of the Corporations Law (1990) states that a prospectus shall contain:

...all such information as investors and their professional advisers would reasonably require, and reasonably expect to

included in this study, as discussed in the next section.

4. Understanding an IPO company's predictive ability also has implications for disclosure regulation in that systematic forecasting biases might be associated with particular elements of the market. This could render mandated forecast disclosure inappropriate in some contexts, with a policy of encouragement or prohibition being reasonable in others. Potential litigation arising from inaccurate forecasting is an ongoing concern of company management and regulatory bodies, with an increasing focus upon disclosure and penalty mechanisms to discourage misrepresentation and increase the accountability of directors, promoters and other parties to an IPO prospectus [Hartnett (1990), Pedwell et al. (1994), Mak (1996)]. Forecast accuracy research can provide guidance as to the control management has over forecasting error (and thus the appropriateness of ascribing responsibility) and the relative influence of fundamental business characteristics upon management's forecasting ability (such as business age, size, industry, forecast interval, etc.). The extent to which IPO forecast error remains unexplained is also informative, for it suggests the existence of other less observable factors, ranging from the random occurrence of unforeseen events to systematic management disclosure strategies motivated by less obvious influences e.g. agency conflicts, funding constraints [Pownall et al. (1989), King et al. (1990), Healy and Palepu (1993), Frankel et al. (1995)].

5. The provision of voluntary forecast information in prospectuses appears to vary cross-sectionally with company characteristics and other factors, and is itself a disclosure phenomenon not yet readily understood [Trueman (1986), Hartnett (1990), Gibbins et al. (1992), Mak (1996)]. 
find, in the prospectus, for the purpose of making an informed assessment of ... the assets and liabilities, financial position, profit and losses, and prospects of the corporation ...

The inclusion of management forecasts in IPO prospectuses would therefore seem a natural consequence of such legislation. Nevertheless, forecast disclosure practices continue to attract much attention in Australia and other countries. Central to the controversy is the question of accuracy. ${ }^{6}$

This study contributes to the international literature on IPO financial forecast disclosure in four key areas. First, the study provides contemporaneous evidence of the error in both revenue and profit forecasts of Australian IPO prospectuses. This complements earlier research by evidencing the extent to which forecast error behaviour might be generalised across differential institutional contexts and performance measures. Second, conventional ex-post modelling of management forecast error is extended by incorporating several new proxies for an IPO's forecasting risk into multiple regression analyses. These new variables are float motive, subscription price premium, range of activities and international exposure. Also, some proxies used in previous studies (notably business age and macroeconomic and industry effects) have been refined. Third, insight is provided into the association between earnings forecast error and conventional risk proxies used for explaining IPO underpricing, thereby recognising an explicit link between

6. Discussion of forecast inaccuracy is widespread in the market place. For example:"Casinos' stock plunges after downgrade ...Casino Australia's latest forecast came just after three month's after the group reassured investors that a strong finish to the year would enable it to meet prospectus forecasts" [Australian Financial Review (9 February 1996) p. 40]; "David Jones finally admitted yesterday that its prospectus forecasts for earnings are too bullish, and almost halved its growth predictions for the full year" [Australian Financial Review (30 April 1996) p.1]; "The ASC is rightly concerned about investors' possible over-reliance on these forecasts" [ASX Journal (January 1997) p.4]; "Network is the latest example of prospectus forecasts which prove impossible to achieve" [Australian Financial Review (24 February 1997) p.60]; "[The] Crown Casino case exposes forecasts ... In the US, profit forecasts and other forward-looking statements are essentially banned" [Australian Financial Review (25 February 1997) p.60]. " ...a fierce battle has broken out between the board of Telstra and the advisers to its $\$ 10$ billion float over key profit projections...The board is determined to resist what it regards as unrealistically optimistic earnings forecasts...[that] will form the basis of the market's valuation of Telstra...If the board gets its way, the potential sale proceeds from the float could be slashed by hundreds of millions of dollars" [Australian Financial Review (31 July 1997) p.1]. 
IPO management's forecasting uncertainty, IPO pricing, and risk proxies. Fourth, ex-ante explanatory variables are distinguished from conventional ex-post modelling variables and an error prediction model is developed using these variables. Whilst all explanatory variables are observable after the fact (ie. ex-post), only some are observable beforehand (ex-ante). To date, research has attempted to identify key determinants of forecast error, but only ex-ante variables can be applied in judging the likely accuracy of a current forecast. Measures of actual economic volatility over the forecast interval are examples of determinants that are only observable ex-post. Such research is of course informative to the understanding of forecast reliability, yet does not really consider forecast error predictability. The most significant issue is whether ex-ante information commonly available to potential IPO investors can be effectively utilised to predict forecast error.

The results show revenue forecast errors were smaller and less sensitive than those for profit. Strong associations were reported between forecast error and float motive, audit quality and unanticipated industry activity. The link between IPO forecasting error and key underpricing risk proxies is observed. Predictability appears poor regarding individual company forecast error, but improves for the average forecasting error across a portfolio of companies.

The remainder of the paper has four main sections. First, the determinants of IPO forecasting error are considered and hypotheses formulated. Second, data collection and sample characteristics are summarised. Third, the study's results are presented and analysed. Finally, conclusions are discussed.

\section{Determinants of Forecast Error and Hypothesis Devolopement}

IPO forecasts have been analysed across several contexts and with respect to numerous proxies for forecasting risk and error. Hypothesised associations have been discussed repeatedly in the literature and the essential arguments are outlined with the hypotheses development, below. Table 1 shows the key studies, the 13 error determinants considered to date, and their observed significance. 
It can be seen that with the exception of forecast interval, the more commonly analysed variables have only been sporadically associated with forecast error to a statistically significant degree. Researchers have not identified a set of company, industry or macroeconomic variables that consistently explains IPO forecast error. It is suggested that alternative firm-specific variables might better capture degrees of uncertainty regarding a post-float stream of earnings and that variables developed previously to proxy forecasting risk may prove more robust with finer calibration.

In this study, 11 variables are investigated as potential determinants of revenue and profit forecast error: age, size, forecast interval, equity retained by pre-offer owners, industry conditions, macroeconomic conditions, audit quality, float motive, subscription price premium (over shareholder funds per share), range of activities and international exposure. The first seven have been utilised in prior forecast error research, in one form or other. The remaining four have not yet been investigated.

Note that some of the variables considered in prior studies (from table 1: float year, leverage, underwriter, profit volatility, and type of issue) are not included in this study. In particular, float year was considered to be a coarse proxy for other underlying factors of potential influence, notably industry and economic conditions and regulatory changes [e.g. Chan et al. (1996)]. Regulatory change was not a feature during the period of this study, with float year consequently subsumed by the industry and macroeconomic variables. Financial leverage was not a relevant variable, given the nature of forecast items used in this study (revenue and, generally, earnings before interest and tax). It is conceivable that the underwriter might influence forecast error via differential monitoring expertise and/or motivations to protect reputation capital. However, there is no readily available Australian underwriter hierarchy for classification purposes. Also, a correlation between the quality of underwriters and other regulatory agents (notably the forecast auditor) was likely. Consequently, underwriter was not investigated. The proxy for growth prospects proposed by Lee et al. (1993a) is not tested in this study, but a similar measure (subscription price premium) is investigated in the context of two competing hypothesised relationships with forecast error. Further, the concept of business growth as a proxy 
for forecasting risk is explored more directly via the motive variable. Profit volatility was excluded as many floats revealed very little (or no) prior trading data upon which to compile a volatility measure. However, it is suggested that industry and macroeconomic activity would reflect the broader determinants of such profit volatility (being the nature of revenue market cycles and cost structures). Most studies of forecasting error in a capital raising context have limited their analyses to IPOs i.e. new share issues, for sample homogeneity and ease of data collection. Consequently, the type of equity issue has not been of great concern in the literature and was considered outside the scope of this study. The 11 variables used in the study are discussed below.

Age

Earlier studies have generally measured age as the time elapsed since the IPO company incorporated or its operating history, and as a dichotomous variable. Age of the underlying business is used in this study (point estimate based on available continuous data), as the earlier alternatives can provide ambiguous measures and may not accurately proxy the underlying influence of true age upon forecast accuracy (i.e. older, more mature businesses are more likely to have established trading histories and stable growth patterns, conducive to greater forecasting precision). A negative association is hypothesised between age and forecast error.

Size

Size is included notwithstanding the insignificant outcomes from prior studies. It remains intuitively appealing to expect that business size reflects underlying factors of relevance to forecasting risk. Larger firms might enjoy lower forecasting error through their ability to better absorb/smooth unexpected financial events, more sophisticated forecast techniques or the regulatory effect of the market scrutinising larger firms more closely due to their higher profile. Alternatively, a positive association between size and error can be posited, as the management of smaller IPO firms may perceive the market as being more tolerant of error from larger firms or that discretionary/smoothing activity might be more typical of smaller firm management [Ferris and Hayes (1977)]. 
Consequently, a non-directional association is hypothesised. Post-float assets are used as the proxy.

\section{Forecast Interval}

Forecast interval is calculated as the number of days from prospectus date to the end of the forecast period. It is expected that the longer the time remaining, the more uncertain management will be regarding future possible events. A positive association with forecast error is hypothesized.

\section{Equity Retained by Pre-Offer Owner/Entrepreneur}

The proportion of post-offer equity held by pre-offer owners may reflect forecast integrity and proxy forecasting risk. For example, a lower proportion may lessen their concern about forecast error and adverse reputation effects, and possibly tempt inflation of the forecast to maximize fundraising. Higher levels of retained ownership may signal higher confidence and forecast achievability. The percentage of post-offer ordinary equity to be held by pre-offer owners is used as the risk proxy in this study. The expected post-offer ownership structure is usually tabled in each prospectus or readily determined from the document. A negative association between forecast error and equity retained is hypothesized.

\section{Industry Conditions}

Due to differences in industry sector cost structures and revenue volatility, industry type is generally anticipated to influence forecast error. Prior studies have used stock exchange industry groups when analyzing forecast error. However, due to small sample sizes, groups are typically merged into only two or three classifications, each comprising numerous and quite diverse industries. This could explain the lack of association found in past studies between forecast error and industry classification despite the strong a priori grounds for expecting a relationship. Since combining sectors can only serve to mask differences in forecast error across industries, better approaches might be employed.

In this study two measures of industry effect upon forecast error are considered. An ex-ante classification is based upon Australian Stock Exchange (ASX) industry codes, with eight industry groups 
distinguished. Over-merging of categories was avoided to preserve observable forecast error differences, if any. An ex-post measure is based upon industry economic activity for each company. Since management's forecasting ability is related to the predictability of industry activity, unexpected activity should bring greater forecasting error. The gap between predicted and actual activity is measured as the absolute difference (expressed as a percentage of expected activity) between (1) actual industry sector contribution to unadjusted gross domestic product (GDP) for the economic quarters of the forecast interval and (2) "expected" sector GDP for those quarters, calculated by reference to the average of the previous four quarters' GDP prior to prospectus date. Data for 31 industry sectors were obtained from the Australian Bureau of Statistics. A positive association is hypothesised between "unexpected" industry GDP and forecast error.

\section{Macroeconomic Conditions}

Prior studies have measured various aspects of economic conditions as potential explanatory variables of forecast error (see table 1). Year of the float, growth in GDP, GDP itself and change in stock exchange indices are the measures used to date. Where GDP was involved, constant values were employed and some measures represented seasonally adjusted trend data. This study uses nominal dollar, unadjusted GDP data to measure changes in economic conditions, since these numbers are considered to better reflect the events of a period and the nominal dollars forecasted and reported. As with industry, a measure of unexpected domestic economic activity is calculated, taken as the absolute percentage difference between: (1) actual GDP for the economic quarters of the forecast, and (2) "expected" GDP, calculated by reference to the average of the four quarters' GDP prior to the prospectus date. A positive association is hypothesised between "unexpected" GDP and forecast error.

\section{Audit Quality}

Quality of the forecast audit is proxied using an auditor dichotomy, distinguishing "Big 5" auditors (formerly Big 8/Big 6) from "Non-Big 5" auditors. There is some disagreement in the literature as to how audit 
quality might affect forecast error, the issue focusing upon the relative influence an auditor might have upon the forecast process vis-à-vis the reporting of actual results [Pedwell et al. (1994)]. Consequently, a non-directional relationship is hypothesised between audit quality and forecast error.

\section{Float Motive}

Motives for an IPO can vary. Some floats represent a stakeholder restructuring, where debt is replaced with new equity or existing businesses sold to new owners. Revenue and earnings behaviour (before financing costs) are essentially unaffected. Other floats are motivated by the expansion of existing activities, or the research and development of new products. Since floats for expansion arguably involve greater uncertainty than for stakeholder restructuring, forecast error is hypothesised to be higher with expansion and lower with restructuring. Motives are categorised for this study by reference to prospectus data (e.g. specific investment plans, expenditure timetables, etc).

\section{Subscription Price Premium over Net Assets}

Lee et al. (1993a) hypothesised a positive association between forecast error and the "premium" $(P)$ of the offered subscription price $(S P)$ over net tangible assets per share (NTA), suggesting the premium [i.e. $P=$ $(S P-N T A) / S P]$ proxies growth opportunities and uncertainty of future operations. No statistically significant association was reported. It is suggested that the premium $\left(P^{*}\right)$ of $S P$ over total shareholders' equity (i.e. net asset backing per share $N A$ ) could similarly proxy the growth option vis-à-vis assets in place $\left[P^{*}=(S P-N A) / S P\right]$. However, the premium could also signal management/promoter confidence regarding the likelihood of business outcomes. The premium might thus reflect a type of "price" for likely favourable future performance. Given the alternative interpretations, a non-directional relationship between the subscription price premium and forecast error is hypothesised. The potential significance of this proxy to IPO underpricing has been noted in the more recent literature, with mixed results [Lee et al. (1993b), How et al. (1995)]. 


\section{Range of Activities}

The number of distinct business segments of a company could influence its forecast precision. Fewer activities might facilitate easier forecasting and thus lower error. Alternatively, multiple activities might serve to "diversify" forecasting risk and thus result in lower error. Companies were classified as single activity (or with a homogeneous set of activities) or multiple activity. Information was sourced from the prospectus. A non-directional association with forecast error is hypothesised.

\section{International Exposure}

This variable proxies business complexity and related risk. Each firm is categorised according to whether it is essentially domestic in nature, an exporter/importer, or a full multinational business located in several countries. Firms with greater "internationalization" could be expected to experience more diverse sources of risk. Consequently, greater forecast error might be expected. Alternatively, as with activities, a diversification effect might reduce forecasting error. Further, the effect might differ between revenue and profit forecasting ability. Information was obtained from the prospectus. A non-directional relationship with forecast error is hypothesised.

\section{Data Collection \& Sample Characteristics}

A random sample comprising 203 IPOs was obtained from ASX listing data for the period from 1991 to June $1996 .^{7}$ Prospectus information was obtained from the company or the ASX. A total of 134 forecasts were identified. Actual results were obtained from the annual reports for the forecast year. Care was taken to properly match the type of revenue and profit reported in the annual report with the type forecasted, an aspect apparently ignored in prior studies. In the case of revenue, total

7. This sample size represented $75 \%$ of the total IPO listings of that period, and was considered large enough to provide sufficient incidence of forecast disclosures for subsequent analysis. 
revenue forecasted was matched with total revenue achieved. Matching profit numbers was more problematic, in that the "bottom line" being forecasted clearly differed amongst firms. For example, most firms forecasted "earnings before interest and tax", and so that profit measure was the one sought from the annual report. Other forms of forecasted profit included "net profit before tax", "net profit after tax" and "earnings before tax, interest, depreciation and amortisation" and these were matched with their respective actual counterparts. Thus a "family" of profit numbers formed the basis of analysis. It was recognized that particular profit classifications might be more susceptible to arbitrary measurement or manipulation by management to reduce observed discrepancies between actual and forecasted results (e.g. net profit before interest and tax might be more easily manipulated than earnings before tax, interest, depreciation and amortisation, due to the inclusion of intangible writeoffs). To help ensure no particular profit type was confounding the error size across the sample, profit forecast error homogeneity was investigated and demonstrated across the different profit classification subgroups. Due to revised reporting periods and other matching difficulties, only 114 revenue and 123 profit forecasts proved amenable to further analysis. Forecast errors $(F E)$ and absolute forecast errors (AFE) were calculated as follows:

$$
\begin{gathered}
F E=\frac{\text { Actual }- \text { Forecast }}{\text { Forecast }} \times 100 \%, \\
A F E=\frac{\mid \text { Actual }- \text { Forecast } \mid}{\mid \text { Forecast } \mid} \times 100 \% .
\end{gathered}
$$

Descriptive statistics pertaining to company characteristics (age, forecast interval, company and float size, industry, float motive, audit quality, range of activity and international exposure) are summarised in tables 2 to 5, revealing a diversity of characteristics to be analysed against forecast error. 
TABLE 2. Age, Forecast Interval, Company and Float Size

\begin{tabular}{lcrrrr}
\hline Variable & Mean & Median & SD & Max & Min \\
\hline Age (years) & 21.27 & 14.41 & 20.67 & 91.78 & .10 \\
Forecast Interval (days) & 218.3 & 240.00 & 134.79 & 933.00 & 1.00 \\
Size (pre float assets: \$m) & 328.5 & 34.50 & 1112.01 & 8407.10 & .10 \\
Size (post float assets: \$m) & 338.5 & 42.20 & 1104.32 & 8407.10 & 4.10 \\
Float Size (\$m) & 108.22 & 17.30 & 287.45 & 2150.00 & 1.00 \\
\hline
\end{tabular}

TABLE 3. Industry Group

\begin{tabular}{lr}
\hline Industry Group & $n$ \\
\hline 1. Resources & 9 \\
2. Building \& Property & 14 \\
3. Financial Services & 12 \\
4. Retail & 7 \\
5. Media & 9 \\
6. Food \& Alcohol & 13 \\
7. Miscellaneous Services & 31 \\
8. Miscellaneous Industrials & 30 \\
Total & 125 \\
\hline
\end{tabular}

\section{TABLE 4. Float Motive}

Float Motive

1. To fund stakeholder restructuring (eg. Debt/equity swap, increase shareholder spread, buyout owners of business).

2. To fund expansion into yet to be identified growth opportunities (eg. Expansion of working capital base, prudent business acquisitions, etc.).

3. To fund expansion of going concern business into identified infrastructures and strategies within existing concern.

4. To fund expansion of start-up or going concern businesses into activities with less tangible outcomes eg. Further exploration, research and/or development of unproven product or service. 
TABLE 5. Audit Quality, Range of Activity and International Exposure

\begin{tabular}{ll}
\hline Variable & $n$ \\
\hline A. Auditor: & \\
Big 5 & 93 \\
Non-Big 5 & 32 \\
Total & 125 \\
& \\
B. Activities: & \\
Single & 98 \\
Multiple & 27 \\
Total & 125 \\
& \\
C. International Exposure: & \\
Domestic & \\
Export/Import & 33 \\
Multinational & 51 \\
Total & 41 \\
\hline
\end{tabular}

\section{Analysis of Results and Discussion}

\section{A. Overall Forecast Error and Bias}

Observed forecast errors for the overall sample are summarised in tables 6 and 7. As shown in table 6, absolute profit forecast errors were high on average and the error distribution quite wide $(M=88.29, S D=$ 297.00). This was less pronounced for revenue forecasts $(M=18.00$, $S D=35.31)$ suggesting that profit is more complex to forecast than revenue. This is reasonable given that revenue is only one element of a profit forecast. The median errors in table 6 , and the analysis of error distributions provided in table 7 , reveal greater precision than that suggested by the mean errors: 60 percent of revenue forecasts and 40 percent of profit forecasts were within 10 percent of the actual result. Statistically significant underestimation bias was also noted, for both the revenue forecasts $(Z=2.801, p<0.01)$ and earnings forecasts $(Z=$ 4.148, $p<0.001)$. 
TABLE 7. Forecast Error Distribution and Bias

\begin{tabular}{|c|c|c|c|c|}
\hline \multirow[b]{2}{*}{ Range of Absolute Errors } & \multicolumn{2}{|c|}{ Revenue } & \multicolumn{2}{|c|}{ Profit } \\
\hline & $n$ & $\%$ & $n$ & $\%$ \\
\hline $\mathrm{AFE} \leq 5 \%$ & 43 & 37.72 & 28 & 22.76 \\
\hline $5<\mathrm{AFE} \leq 10 \%$ & 26 & 22.81 & 22 & 17.89 \\
\hline $10<\mathrm{AFE} \leq 25 \%$ & 27 & 23.68 & 22 & 17.89 \\
\hline $25<\mathrm{AFE} \leq 50 \%$ & 9 & 7.89 & 16 & 13.01 \\
\hline $50<\mathrm{AFE} \leq 100 \%$ & 8 & 7.02 & 20 & 16.26 \\
\hline $100 \%<\mathrm{AFE}$ & 1 & 0.88 & 15 & 12.19 \\
\hline Total & 114 & 100 & 123 & 100 \\
\hline $\begin{array}{l}\text { Bias associated with } \\
\text { Forecast Error Number } \\
\text { of overestimated forecasts }\end{array}$ & \multicolumn{2}{|c|}{49} & \multicolumn{2}{|c|}{50} \\
\hline $\begin{array}{l}\text { Number of underestimated } \\
\text { forecasts }\end{array}$ & \multicolumn{2}{|c|}{65} & \multicolumn{2}{|c|}{73} \\
\hline $\begin{array}{l}\text { Sign (Fisher) Test for } \\
\text { estimation bias (large } \\
\text { sample Z-statistic) }\end{array}$ & \multicolumn{2}{|c|}{$2.8 \#$} & \multicolumn{2}{|c|}{$4.15 \dagger$} \\
\hline
\end{tabular}

Note: Significant at .01(\#) and .001(†) respectively.

\section{B. Forecast Error Determinants Observable Ex-Post}

\section{Univariate Statistics: Method and Results}

Pair-wise correlations were calculated for all independent variables and $A F E$ s. These are shown in table 8 with associated levels of significance. Statistically significant correlations were observed between Revenue $A F E$ and age, forecast interval, economic conditions, float motive, subscription price premium and audit quality. Regarding profit forecasts, significant correlations were observed between Profit $A F E$ and age, forecast interval, industry, economic conditions, float motive and audit quality. Each comparison displayed the hypothesised direction of association (where relevant).

The correlation between forecast error and categorical variables was confirmed by conventional parametric analyses of two or more sample distributions, namely Student-t tests of sample means and Analysis of Variance and corroborated with non-parametric tests. For brevity, these 


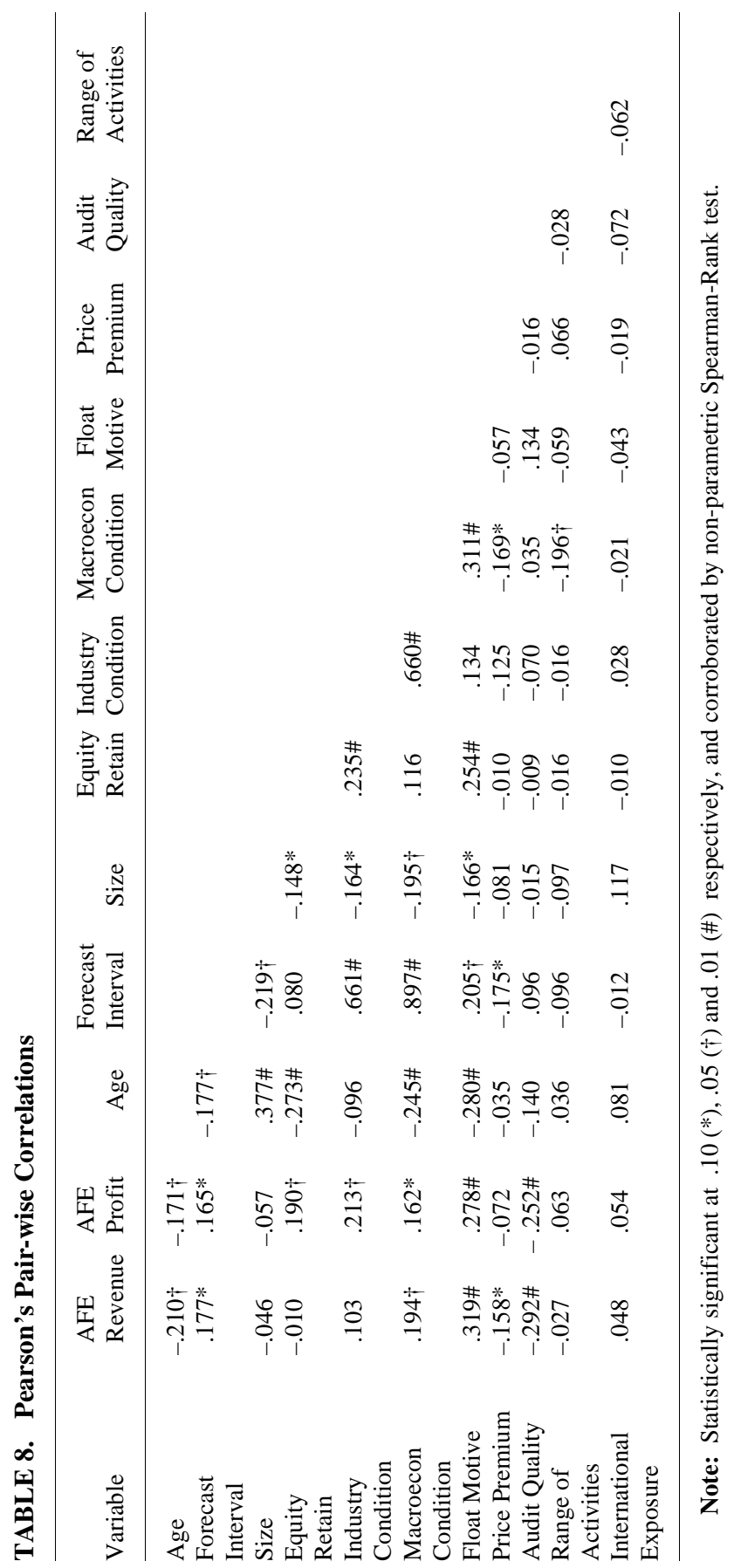


results have not been tabulated but instead the key features are noted. The association between forecast error and float motive was significant at the 0.01 level for both revenue and profit forecasts. This is consistent with the proposition that forecast error varies with the uncertainty of future earnings arising from the float. An inverse relationship was observed between auditor quality and forecast error. This association was significant at the 0.01 level, suggesting forecast precision is enhanced by higher quality auditors. This is contrary to the neutral and positive associations reported by earlier research in other settings. ${ }^{8}$ No statistically significant difference was observed for any of the remaining three categorical variables: industry (ASX sector), range of activities and international exposure. High variability in forecast error across categories limited the likelihood of significant differences.

\section{Multivariate Statistics: Method and Results}

Further investigation of forecast error was undertaken using multiple regression techniques. Consideration of key regression assumptions highlighted the need for some re-specification of the proposed regressions. Although parametric statistics are considered robust to some non-normality, the skewed distributions of the sample $A F E$ s and preliminary regression residuals precluded the confident acceptance of the assumptions of normality and variance homoscedasticity. Consequently, logarithmic transformations of AFEs were used in all multiple regression analyses, with residual normality and homoscedasticity now readily observed. ${ }^{9}$

A second issue concerned multicollinearity. The correlation

8. The neutral effect of audit quality reported in both the UK study by Keasey and McGuinness (1991) and the Hong Kong study by Chan et al. (1996) is possibly explained by the similar institutional and regulatory environments (Hong Kong being under British control until mid 1997). Since companies are required to explain substantial discrepancies between forecast and actual results, it is foreseeable that the quality or reputation of the audit firm is unlikely to have a significant differential effect upon forecast error. The positive association reported in Pedwell's Canadian study (1994) suggests that higher profile auditors place less emphasis on forecast veracity and attach more importance to regulating the potential for companies to smooth actual results to better coincide with forecasts. The opposite is implied by the present study in the Australian environment.

9. See Weisberg (1985 pp. 133-134). Also, for completeness, pair-wise correlations between variables were recalculated using $L n A F E$, and reflected very similar associations as observed with $A F E$. 
coefficients in table 8 reveal significant correlations between forecast interval, industry and macroeconomic conditions and between age, retained equity, forecast interval, size, macroeconomic conditions and float motive. In addition to these reported correlation coefficients, preliminary regression analysis using all 11 independent variables also indicated multicollinearity. ${ }^{10}$ To ameliorate any suspected distortions resulting from this multicollinearity, the ex-post regression models were revised with the elimination of age, forecast interval and unexpected macroeconomic conditions. ${ }^{11}$ The regressions were thus limited to eight independent variables, namely company size, equity retained, unexpected industry conditions, float motive, subscription price premium, audit quality, range of activities, and international exposure.

The revised regression model for Revenue Ln $A F E$ was calculated with results summarised in table 9 below. The model was significant $(p$ $=0.0082$ ) but with an adjusted $R^{2}$ of only $12.68 \%$. Industry, motive and audit quality were all significantly associated with forecast error and directions of association were as hypothesised. Equity retained by pre-offer owners, company size, subscription price premium, range of activities and international exposure were not significant.

Similarly, the ex-post regression model for Profit Ln $A F E$ was limited to the eight independent variables used in the revenue error analysis.

10. Where a number of independent variables measure essentially the same factor (which appears to be the case here) the resultant multicollinearity will cause factor coefficients to split across the collinear variables. This can lead to the conclusion that one or all of the collinear variables are not statistically significant, with low $F$-statistics and yet magnified $R^{2}$ s for the overall model [Pedhazur (1982 p. 242), Younger (1985 p. 449)]. By way of illustration, the regression for the entire 11 independent variables for the Ln Revenue AFE revealed a statistically significant regression model $(p=.0173)$, with an adjusted $R^{2}$ of $12.09 \%$. Although the overall model was significant, the only significant variable was the intercept term.

11. Before finalizing the regression models a range of factors were considered: (i) levels of association between key independent variables reported in the pair-wise correlation analysis of table 8; (ii) confirmation of collinearity problems via preliminary regressions of all variables (see previous endnote); (iii) a priori reasoning suggesting float motive is a finer measure of risk; i.e. older companies might also pursue growth motives which entail more risk (refer to discussion in paper); (iv) stepwise regression confirming strength of float motive over age and over alternative regression models which included age but with increased interaction noise; and (v) a priori reasoning suggesting unexpected industry conditions is a finer measure of risk than unexpected macroeconomic conditions or forecast interval. 
TABLE 9. Revenue Forecast Error Determinants using Multiple Regression

\begin{tabular}{|c|c|c|c|c|c|}
\hline Independent Variables & $\begin{array}{l}\text { Regression } \\
\text { Estimate }\end{array}$ & $t$-statistic & Prob $>|t|$ & $\begin{array}{c}\text { F- } \\
\text { statistic }\end{array}$ & Prob $>F$ \\
\hline Intercept & 1.89871 & 4.96 & $<.0001$ & & \\
\hline Size & -.00008 & -.54 & .5919 & & \\
\hline Equity Retained & .00014 & .02 & .9807 & & \\
\hline Industry & 2.05661 & 2.57 & .0116 & & \\
\hline Subscription Price Premium & -.00056 & -.51 & .6086 & & \\
\hline Float Motive: & & & & 2.49 & 9.0644 \\
\hline Restructure & -.38410 & -1.63 & .1070 & & \\
\hline Expansion: Non-specific & -.55047 & -1.62 & .1082 & & \\
\hline Expansion: Identified & .05372 & .19 & .8481 & & \\
\hline Expansion: R \& / Exploration & .88086 & 2.33 & .0216 & & \\
\hline \multicolumn{6}{|l|}{ Audit Quality } \\
\hline Big 5 & -.33416 & -2.01 & .0466 & & \\
\hline Non-Big 5 & .33416 & 2.01 & .5000 & & \\
\hline \multicolumn{6}{|l|}{ Range of Activities } \\
\hline Single & .11948 & .68 & .5000 & & \\
\hline Multiple & -.11948 & -.68 & .5000 & & \\
\hline International Exposure: & & & & .47 & 7.6257 \\
\hline Domestic & -.03430 & -.16 & .8751 & & \\
\hline Import/Export & -.13559 & -.69 & .4892 & & \\
\hline Multinational & .17000 & .89 & .3775 & & \\
\hline Model: $R^{2}=21.18 \%$ & & & & 2.49 & 9.0082 \\
\hline \multicolumn{6}{|l|}{ Adj $R^{2}=12.68 \%$} \\
\hline$n=114$ & & & & & \\
\hline
\end{tabular}

Note: For each categorical variable having $g$ subgroups, the regression equation incorporates $k=g-1$ regression estimates (i.e., treatment effects or coefficients) corresponding to the first $g-1$ vector codes used to input the categorical data. Using effect coding (sometimes called sum-to-zero coding) the last subgroup's treatment effect (say $b_{i}$ ) has the property $b_{i}=-\Sigma b_{k}$ such that the treatment effects (coefficients) have a "sum-tozero". The treatment effect for the final subgroup is thus readily derived from the regression data and simply shown here to assist interpretation of results. For more on effect coding, see Pedhazur (1982). The F-statistic is shown for categorical data with more than 2 subgroups to indicate overall effect of the variable. For continuous variables, and categorical variables with only 2 subgroups, the F-statistic is not shown, for it is simply the square of the $t$ statistic, and probabilities are identical.

The overall model for Profit Ln $A F E$ was significant ( $p<0.0001$ ), with an adjusted $R^{2}$ of $27.53 \%$. Statistically significant associations were 
observed between Profit Ln $A F E$ and industry, float motive and audit quality. The directions of association were as hypothesised. As was the case for the revenue error analysis, no significant associations were observed for the other five independent variables. Table 10 summarises the results.

\section{Discussion of Univariate and Multivariate Results}

The observed forecast error distributions and significant associations represent novel contributions to the literature on forecast error behaviour and the IPO underpricing phenomenon. The inclusion of the revenue forecast error analysis is informative in that revenue forecasts are observed to be generally more accurate than profit forecasts (recall tables 6 and 7). They also appear less sensitive to variation in the risk proxies as evidenced by the significant, yet relatively low $R^{2}$ of the revenue error regression model. This suggests that the accuracy of the revenue component of financial forecasts is more closely linked to the existence of contracts, forward orders, or readily defined elements such as interest earnings during the forecast interval. Profit forecasts are more problematic, and error is better defined by the key independent variables used to proxy forecasting risk.

The significance of float motive, audit quality and industry conditions is instructive. Float motive has not been analysed before in the context of forecast error and its statistical significance suggests an alternative direction for future research in that area. The findings are also consistent with the IPO pricing literature where evidence of a relationship has been reported between motive ("purpose" or "use of proceeds" is the term used in the literature, and with different classifications to those used by us) and underpricing [Jog and Riding (1987)]. The study confirms that differing float motives can be associated with the precision of an IPO's financial forecast and thus the proposition that underpricing reflects the riskiness of forecasted earnings streams is supported. The association between auditor quality and forecast error has not been analysed in the Australian context and when considered elsewhere, was either not significant or displayed a positive association. This is contrary to the strong inverse relationship observed in this study. It is difficult to postulate a reason for these contrary effects but, as discussed earlier, they may reflect differing regulatory environments across studies with regard to forecast appraisal vis-à-vis 
TABLE 10. Profit Forecast Error Determinants Using Multiple Regression

\begin{tabular}{|c|c|c|c|c|c|}
\hline \multirow[b]{2}{*}{ Independent Variables } & \multicolumn{2}{|c|}{ Regression } & \multirow[b]{2}{*}{ Prob $>|t|$} & \multirow{2}{*}{$\begin{array}{c}\text { F- } \\
\text { statistic }\end{array}$} & \multirow[b]{2}{*}{ Prob $>F$} \\
\hline & Estimate & $t$-statistic & & & \\
\hline Intercept & 2.8635 & 7.30 & $<.0001$ & & \\
\hline Size & -.00020 & -1.37 & .1734 & & \\
\hline Equity Retained & .00272 & .45 & .6531 & & \\
\hline Industry & 3.24342 & 3.53 & .0006 & & \\
\hline Subscription Price Premium & -.00111 & -.90 & .3726 & & \\
\hline Float Motive: & & & & 2.23 & .0885 \\
\hline Restructure & -.45033 & -1.78 & .0771 & & \\
\hline Expansion: Non-specific & -.42230 & -1.20 & .2334 & & \\
\hline Expansion: Identified & -.17306 & -.54 & .5914 & & \\
\hline Expansion: R \& / Exploration & 1.04569 & 2.42 & .0172 & & \\
\hline \multicolumn{6}{|l|}{ Audit Quality } \\
\hline Big 5 & -.81713 & -4.65 & $<.0001$ & & \\
\hline Non-Big 5 & .81713 & 4.65 & .0001 & & \\
\hline \multicolumn{6}{|l|}{ Range of Activities } \\
\hline Single & .02148 & .11 & .9104 & & \\
\hline Multiple & -.02148 & -.11 & .9104 & & \\
\hline International Exposure: & & & & .15 & .8592 \\
\hline Domestic & -.02378 & -.10 & .9198 & & \\
\hline Import/Export & .11002 & .51 & 6109 & & \\
\hline Multinational & -.08624 & -.40 & .6913 & & \\
\hline Model: $R^{2}=34.07 \%$ & & & & 5.21 & $<.0001$ \\
\hline \multicolumn{6}{|l|}{$\operatorname{Adj} R^{2}=27.53 \%$} \\
\hline$n=123$ & & & & & \\
\hline
\end{tabular}

Note: For each categorical variable having $g$ subgroups, the regression equation incorporates $k=g-1$ regression estimates (i.e., treatment effects or coefficients) corresponding to the first $g-1$ vector codes used to input the categorical data. Using effect coding (sometimes called sum-to-zero coding) the last subgroup's treatment effect (say $b_{i}$ ) has the property $b_{i}=-\Sigma b_{k}$ such that the treatment effects (coefficients) have a "sum-tozero". The treatment effect for the final subgroup is thus readily derived from the regression data and simply shown here to assist interpretation of results. For more on effect coding, see Pedhazur (1982). ${ }^{2}$ The F-statistic is shown for categorical data with more than 2 subgroups to indicate overall effect of the variable. Note for continuous variables, and categorical variables with only 2 subgroups, the F-statistic is not shown, for it is simply the square of the $t$-statistic, and probabilities are identical.

the audit of actual results. As with float motive, the audit quality analysis evidences the link between key risk proxies used in the IPO pricing 
literature and earnings forecast risk. Unexpected industry activity appears a useful proxy for the forecasting risks associated with forecasting interval, industry type and macroeconomic conditions, and so provides the basis for an important explanatory variable in future replicative research. The findings are again consistent with the literature where industry type and industry activity have been associated with underpricing [Ritter (1984), Jog and Riding (1987)]. The link between those risk proxies, earnings forecast risk and underpricing is supported.

The non-significance of the five other variables (equity retained by pre-offer owners, size, subscription price premium, range of activities and degree of internationalization) is of interest, given their intuitive appeal in explaining variations in forecast error. Classification methods, measurement and use of finer proxies are possible reasons for the non-significance. Specifically, evidence in the IPO literature regarding the significance of equity retained by pre-offer owners to the level of IPO forecast error and/or underpricing has been equivocal to date. Although a significant association was observed by some [Leland and Pyle (1977), Beatty (1989)], no significance was found by others [Jog and Riding (1987)]. It is worth noting that Jog and Riding controlled for "purpose/use of proceeds" in their study of underpricing, as was "float motive" controlled for in this study of forecast error. Thus a plausible explanation for the non-significance of the equity retained variable in studies that controlled for motive is that the equity retained variable is likely to be determined in large degree by the float motive (e.g. fundraising for expansion would likely result in a higher proportion of retained equity than a refinancing to fund a sell-off by the owners). That is, controlling for motive leaves little further explanatory power in the equity retained variable. This association between equity retained and float motive is in fact evidenced in the correlations of table 8. Business size again failed to explain variation in forecast error. It may be that conventional proxies for size (aggregates of book assets, turnover, float size, etc.) do not properly reflect its true differential effect upon forecasting risk. Further, the effect of standardizing raw dollar forecast error by reference to the firm's projected revenue or profit (as traditionally performed to enable a more valid comparison across companies) may serve to mask any relationship between error and size. The non-significance of the offered subscription price premium variable might reflect competing hypothesized effects, for it was discussed earlier 
that the price premium could indicate a high growth plan characterised by more financial uncertainty or a premium for management confidence in the outcomes of the float (the relevant interpretation varying across companies). Alternatively, the reported book value of equity may not allow accurate measurement of true market premiums for safer forecasts [or, alternatively, not allow accurate measure of discounts regarding the growth risk proxy posited by Lee et al. (1993a)], for it is also recognized that the reference point for setting subscription prices in the case of IPOs frequently incorporates market listing price considerations and not simply the above mentioned factors. As with the subscription price premium variable, the non-significance of the range of activity and international exposure variables perhaps reflects the competing nature of alternative hypothesized effects of the variables upon forecast error. Whilst the pattern of errors suggest a possible consistent underlying relationship (especially regarding the international exposure variable), the very low $F$-statistics preclude the likelihood of such a relationship.

The explanatory power of the ex-post regression model for profit forecast error was higher than that observed in prior studies $\left(R^{2}\right.$ $=34.07 \%$, Adj $R^{2}=27.53 \%$ ). It is difficult to further compare the forecast error distributions across these studies given the lack of detailed data generally available. Although all appear to be characterized by extreme outliers, median error is not always reported, nor a breakdown of error and bias distributions. Nonetheless, there does appear to be a trend of increasing forecast accuracy since the late 1980s [e.g. see Goodwin (1989), Mak (1989), Hartnett (1993), Pedwell et al. (1994), Keasey and McGuinness (1991), Chan et al. (1996)].

Finally, it appears that the direction of forecast bias is not a systematic feature across IPO studies. Rather, bias seems to be a characteristic more dependent upon the market setting and period of study. ${ }^{12}$

12. For example, the IPO forecasts analysed in the Australian second board study by Hartnett (1993) displayed overestimation bias and were published in a market characterised by less stringent stock exchange listing rules and prospectus disclosure regulation, and during a time of intense IPO activity prior to the 1987 sharemarket collapse. In contrast, the underestimation bias observed by Keasey and McGuinness (1991) in the UK, and in this present Australian study, may reflect the more regulated disclosure environment and litigation pressures now present in those markets. Goodwin (1989) reported unbiased errors regarding Australian IPO forecasts and Pedwell et al. (1994) reported overestimation bias 


\section{Forecast Error Determinants Observable Ex-Ante}

\section{Method and Results}

The three statistically significant variables observed in the above ex-post analyses were next used to model forecast error using potential determinants that are only available ex-ante. The ex-post proxy for industry effect was replaced with the relevant ASX industry grouping (which is available ex-ante). The regressions based on these variables identified float motive and audit quality, but not industry, as statistically significant (in the case of industry, $p=0.82$ with respect to revenue forecasts, and $p=0.70$ for profit forecasts). Given the lack of explanatory power associated with the ex-ante industry variable, the regressions were recast excluding industry prior to developing the forecast error prediction models. As expected, the respecified regressions again produced highly significant coefficients for float motive and audit quality. Whilst the overall models were significant $(p<0.001)$, the adjusted $R^{2}$ was only $11.31 \%$ in the case of revenue forecast error and $19.18 \%$ for the corresponding profit forecast error model.

\section{Forecast Error Prediction Model}

\section{Method and Results}

The regression models in this study have reported statistically significant associations between the dependent error term and several IPO risk proxies. The null hypothesis of a zero population mean forecast error for the raw error distributions was also tested with the hypothesis rejected at conventional levels. ${ }^{13}$ Also, the article noted earlier that underestimates outnumbered overestimates and this underestimation bias was statistically significant (recall table 7). In precis, the evidence suggests that IPO financial forecasts exhibit a systematic bias such that their expected error is not zero. Consequently it might be possible to incorporate key determinants of forecast error into a prediction model.

with Canadian IPOs.

13. As noted earlier in the paper, the error distributions for both revenue and profit contained several extreme outliers which subsequently distorted the distributions' means and magnified standard deviations. One outlier was eliminated from the revenue forecast error distribution (308.24\%), and four were eliminated from the profit forecast error distribution $(-2918.50 \%,-992.00 \%, 487.93 \%, 1024.70 \%)$. 
Notwithstanding this potential for prediction, the reasonably low $R^{2}$ $s$ reported in the above regression models suggested a likely inability of investors to predict the magnitude of forecast errors from information available in the prospectus. This issue was investigated further. The total sample of 125 forecasting firms was randomly divided into two groups. The first group comprised 95 firms and was used to construct the prediction model. The second group comprised 30 firms and represented the test group to which the prediction model was applied. It was necessary to ensure that the construction sample contained at least 30 variables per independent or predictor variable to avoid over-fitting or overestimation of $R$ (Pedhazur, 1982). The range of actual forecast errors with respect to revenue and profit for the test group were consistent with those of the total forecast sample (refer table 7), and support the overall representativeness of the test group. In aggregate, some $60 \%$ of the revenue forecasts exhibited no more than $10 \%$ error, and approximately $40 \%$ of the profit forecasts were also within this range of error. Estimation bias was again significant.

Regressions using the ex-ante variables of the study's earlier models were performed on the prediction modelling group. The results confirmed that the same two statistically significant ex-ante variables should be used in the prediction model: float motive and audit quality. The prediction regression models were then formulated. The Revenue Ln AFE Prediction Model was significant $(p=0.0008)$ with an adjusted $R^{2}$ of $16.97 \%$. The Profit Ln AFE Prediction Model was also significant $\left(p<0.0001\right.$ ) with an adjusted $R^{2}$ of $21.83 \%$ (for brevity, the detailed regression results have been omitted).

The prediction models were applied to the test group, and predicted forecast errors were calculated. The predicted Ln AFEs were compared with the actual Ln AFEs on an individual "matched" basis using correlation analysis, and on a group-wide basis using conventional pair-wise comparisons of means and ranks (Student $t$ and Wilcoxon Signed-Rank tests). The results are summarized in table 11.

\section{Discussion of Prediction Model Results}

The results indicate that on an individual company basis, correlations between actual and predicted Ln AFEs were low and not statistically significant (Revenue Ln AFE Prediction Model, $r=-.02$ and Profit Ln $A F E$ Prediction Model, $r=.12$ ). On a group-wide basis, the paired 
TABLE 11. Analysis of Forecast Error Prediction Models

\begin{tabular}{lllcccc}
\hline & $n$ & Mean & SD & $n$ & Mean & SD \\
\hline Actual Ln AFE\% & 29 & 1.9735 & 1.1308 & 29 & 2.3307 & 1.7987 \\
Predicted Ln AFE\% & 29 & 1.661 & .7811 & 29 & 2.6446 & .7637 \\
$t$-statistic & & 1.22 & & & .87 & \\
Correlation coefficient & & -.02 & & & .12 & \\
\hline
\end{tabular}

Note: Student- $t$ and correlation results corroborated by non-parametric Wilcoxon Signed-Rank and Spearman-Rank tests.

t-tests (and corresponding non-parametric Wilcoxon tests) revealed that predicted and actual forecast errors were sufficiently similar so as to preclude the rejection of the null hypothesis (of no difference between actual and predicted error). The inability to detect a difference appeared driven by the relatively wide dispersion of error differences around the mean. Confidence intervals for the predicted mean error were quite wide, thereby reducing the useful prediction of this average group-wide error. The results are informative, for they suggest that an ability to identify the company and float characteristics which are significantly associated with forecast error on a market-wide basis is not sufficient for investors to accurately gauge the likely accuracy of any individual prospectus forecast. Much of the research in this area has been devoted to identifying the factors that influence forecast accuracy, presumably to provide investors and others with a "model" upon which to judge future disclosures. The variability of forecast accuracy behaviour would seem to limit such applications at this point. These results are analogous to outcomes in the IPO underpricing literature where predicting the initial returns from an individual offer "is difficult ..., even though the average initial return in a large sample can be predicted with reasonable accuracy” [Beatty and Ritter (1986) p. 223).

\section{Conclusions}

This study examined the accuracy of revenue and profit forecasts disclosed in Australian prospectuses. Whilst revenue forecasts were reasonably accurate; the mean absolute error associated with profit 
forecasts was considerably higher. Nevertheless, analysis of the error distributions revealed greater forecast precision than that suggested by the mean errors; 60 percent of revenue forecasts and 40 percent of profit forecasts were within 10 percent of the actual result. A statistically significant underestimation bias was noted.

Conventional ex-post forecast error modelling was extended by investigating several new variables (float motive, subscription price premium over net assets, range of activities and international exposure) and by refining the proxies for age, industry and macroeconomic conditions used in other studies. Forecast errors were found to be associated with unexpected industry conditions, float motive and audit quality. Float motive was particularly robust and provided at least as much explanatory power as several other traditionally used variables, such as age, forecast interval and size. The motive variable appears to capture age, size and retained equity effects and, to some degree, macroeconomic conditions (for example, firms may be more inclined to pursue growth in a buoyant economy where confidence is high and investor funds are more readily available). The significance of float motive suggests an alternative direction for future research in this area. Forecast error was not significantly associated with company size, equity retained by owners, subscription price premium, range of activities and international exposure.

The significance of float motive, auditor quality and industry activity in forecast error modelling is instructive with regard to IPO underpricing. This study's findings are consistent with the IPO underpricing literature where a relationship has been reported between underpricing and the use of the offer proceeds, auditor reputation and industry. The results provide evidence of the link between key risk proxies used in the IPO underpricing literature and earnings forecast risk, supporting the proposition that underpricing reflects the riskiness of forecasted earnings numbers. A natural extension to this research would be more explicit modelling of underpricing and earnings forecast error.

The study also focused upon the efficacy of forecast error prediction models, since investors are assumed to use demonstrated forecast accuracy to formulate or revise perceptions of future accuracy. The study distinguished between ex-ante and ex-post explanatory variables, and investigated the predictability of forecast error by developing and testing revenue and profit forecast error prediction models based on key 
ex-ante explanatory variables. Overall, the predictability of individual company forecast error was poor. While it may be that many companies in the sample produced quite reliable forecasts, a significant portion reported large errors. Since it would appear that the latter companies cannot be identified through the use of prediction models, the usefulness of forecasts in prospectus disclosures appears questionable in this context.

Emphasis continues to be placed upon research into the determinants of prospectus forecast accuracy and indeed, IPO pricing. Whilst contributions to date have been instructive, none have provided substantial explanations. Importantly, this paper demonstrates that although factors which contribute to a forecasting error can be distinguished ex-post, company characteristics disclosed or derived from the prospectus are not sufficient to predict that forecast error with any degree of reasonable precision. However, the prediction models indicate that investors will, on average across a number of floats, observe a predicted forecast error that is statistically similar to the actual error. This is analogous to conclusions drawn from the underpricing literature, whereby the predictability of initial return from a given offering is quite low, notwithstanding the higher predictability of average initial returns from a larger sample.

\section{References}

Basi, B. A.; Carey, K.J.; and Twark, R.D. 1976. A comparison of the accuracy of corporate and security analysts' forecasts of earnings. Accounting Review (April): 244-254.

Baginski, S. P., and Hassell, J.M. 1997. Determinants of management forecast precision. Accounting Review 72 (2): 303-312.

Beatty, R.P. 1989. Auditor reputation and the pricing of initial public offerings. Accounting Review (October): 693-709.

Beatty, R.P., and Ritter, J.R. 1986. Investment banking, reputation, and the underpricing of initial public offerings. Journal of Financial Economics (January/February): 213-232.

Chalk, A.J., and Peavy, J.W. 1986. Understanding the pricing of initial public offerings. Working Paper. Southern Methodist University.

Chan, A. M. Y.; Sit, C. L. K.; Tong, M. M. L.; Wong, D.C.K.; and Chan, R.W.Y. 1996. Possible factors of the accuracy of prospectus earnings forecast in Hong Kong. The International Journal of Accounting 31 (3): 381-398.

Daily, R. A. 1971. The feasibility of reporting forecasted information. 
Accounting Review (October): 686-692.

Dev, S., and Webb, M. 1972. The accuracy of company profit forecasts. Journal of Business Finance 4 (3): 26-27.

Ferris, K. R., and Hayes, D. C. 1977. Some evidence on the determinants of profit forecast accuracy in the United Kingdom. The International Journal of Accounting (Spring): 27-36.

Frankel, R.; McNichols, M.; and Wilson, G. P. 1995. Discretionary disclosure and external financing. Accounting Review (January): 135-150.

Gibbins, M.; Richardson, A. J.; and Waterhouse, J. 1992. The management of financial disclosure: Theory and perspectives. Vancouver: Canadian Certified General Accountants Research Foundation.

Goodwin, J. 1989. Forecasting in the prospectuses of newly listed companies: Some Australian evidence. Accounting Forum (June): 3-29.

Hartnett, N. A. 1990. Quantitative prospective financial information disclosure by companies listing on the Second Board of the Australian Stock Exchange. Masters Dissertation. Newcastle: University of Newcastle, Australia.

Hartnett, N. A. 1993. Corporate financial forecast accuracy: An Australian study. The International Journal of Accounting 28: 248-258.

Hassell, J. M., and Jennings, R. H. 1986. Relative forecast accuracy and the timing of earnings forecast announcements. Accounting Review (January ): 58-75.

Healey, P., and Palepu, K. 1993. The effect of firm's financial disclosure strategies on stock prices. Accounting Horizons (March): 1-11.

How, J.C.Y.; Izan, H. Y.; and Monroe, G. S. 1995. Differential information and the underpricing of initial public offerings: Australian evidence. Accounting and Finance (May): 87-105.

Imhoff, E. A. 1978. The representativeness of management earnings forecasts. Accounting Review (October): 836-838.

Jaggi, B. 1980. Further evidence on the accuracy of management forecasts vis-à-vis analysts' forecasts. Accounting Review (January): 96-101.

Jog, V. J., and Riding, A. L. 1987. Underpricing in Canadian IPOs. Financial Analysts Journal (November/December): 48-55.

Keasey, K., and McGuinness, P. 1991. An examination of the accuracy and bias of prospectus earnings forecasts: UK evidence. The International Journal of Accounting 26 (4): 252-263.

King, R.; Pownall, G.; and Waymire, G. 1990. Expectations adjustment via timely earnings forecast disclosure: Review, synthesis and suggestions for future research. Journal of Accounting Literature 9: 113-144.

Lee, P.; Taylor, S.; Yee, C.; and Yee, M. 1993a. Prospectus earnings forecasts: Evidence and explanations. Australian Accounting Review (May): 21-32.

Lee, P.; Taylor, S.; and Walter, T. 1993b. Australian IPO pricing in the short and long run. Working Paper. Sydney: University of Sydney.

Leland, H., and Pyle, D. 1977. Information asymmetrics, financial structure, and 
financial intermediation. Journal of Finance (May): 371-387.

Lev, B., and Penman, S. 1990. Voluntary forecast disclosure, nondisclosure, and stock prices. Journal of Accounting Research (Spring): 49-76.

Mak, Y. T. 1989. The determinants of accuracy of management earnings forecasts: A New Zealand study. The International Journal of Accounting 24 (3): 267-280.

Mak, Y. T. 1996. Forecast disclosure by initial public offering firms in a low-litigation environment. Journal of Accounting and Public Policy 15: 111-136.

McDonald, C. L. 1973. An empirical examination of the reliability of published predictions of future earnings. Accounting Review (July): 502-510.

Patell, J. 1976. Corporate forecasts of earnings per share and stock price behaviour. Journal of Accounting Research (14): 246-276.

Pedhazur, E.J. 1982. Multiple Regression in Behavioural Research: Explanation and Prediction. 2nd Edition. New York: Holt, Rinehart and Winston.

Pedwell, K.; Warsame, H.; and Neu, D. 1994. The accuracy of Canadian and New Zealand earnings forecasts: A comparison of voluntary versus compulsory disclosures. International Accounting, Auditing and Taxation 3 (2): 221-236.

Penman, S. H. 1980. An empirical investigation of the voluntary disclosure of corporate earnings forecasts. Journal of Accounting Research (Spring): 132-160.

Pownall, G.; Wasley, C.; and Waymire, G. 1989. Alternative forms of management earnings forecasts: Incidence and stock price effects. Accounting Review (October): 896-912.

Ritter, J. R. 1984. The "Hot Issue" market of 1980. Journal of Business (April): 215-240.

Ruland, W. 1978. The accuracy of forecasts by management and by financial analysts. Accounting Review (April): 439-447.

Simunic, D., and Stein, M. 1987. Product Differentiation in Auditing: Auditor Choice in the Market for Unseasoned New Issues. Research Monograph No. 13. Vancouver: The Canadian Certified General Accountants Research Foundation.

Titman, S., and Trueman, B. 1986. Information and the valuation of new issues. Journal of Accounting and Economics (June): 159-172.

Trueman, B. 1986. Why do managers voluntarily release earnings forecasts? Journal of Accounting and Economics 8: 53-71.

Waymire, G. 1984. Additional evidence on the information content of management earnings forecasts. Journal of Accounting Research (Autumn): 703-718.

Weisberg, S. 1985. Applied Linear Regression. 2nd Edition. New York: John Wiley \& Sons.

Younger, M. S. 1985. A First Course in Linear Regression. 2nd Edition. Boston: Duxbury Press. 